\title{
Parâmetros de desempenho e carcaça de genótipos de frangos tipo caipira
}

\author{
[Performance parameters and carcass of genotypes from \\ alternative strains of broiler chickens] \\ R.C. Veloso ${ }^{1}$, A.V. Pires ${ }^{1}$, R.A. Torres Filho ${ }^{2}$, S.R.F. Pinheiro ${ }^{1}$, \\ L.K. WinKelstroter ${ }^{1}$, D.C. Alcântara ${ }^{1}$, C.C.D.C.S. Cruz ${ }^{2}$ \\ ${ }^{1}$ Universidade Federal dos Vales do Jequitinhonha e Mucuri, MG \\ ${ }^{2}$ Universidade Federal Fluminense - Niterói, RJ
}

\begin{abstract}
RESUMO
Objetivou-se com este trabalho avaliar as características de desempenho e de carcaça de sete genótipos de frangos tipo caipira da linhagem Redbro. Foram utilizados 840 pintos de um dia, machos, distribuídos em delineamento inteiramente ao acaso, dos seguintes genótipos: Caboclo, Carijó, Colorpak, Gigante Negro, Pesadão Vermelho, Pescoço Pelado e Tricolor. Os frangos foram alojados em 28 boxes, sendo 30 frangos por boxe, em galpão de alvenaria com acesso a um piquete de $45 \mathrm{~m}^{2}$, em quatro repetições. As características de desempenho (conversão alimentar, ganho em peso médio diário, consumo de ração médio diário) foram avaliadas nos períodos: um a 28, um a 56, um a 70 e um a 84 dias de idade. $O$ peso corporal foi avaliado aos 28, 56, 70 e 84 dias de idade. As características de carcaça (peso e rendimento de carcaça, peito e pernas) foram obtidas a partir do abate de dois frangos por boxe, aos 85 dias de idade. As análises estatísticas foram realizadas utilizando-se o "proc glm" do SAS. Verificou-se que, em todos os períodos, os frangos do genótipo Colorpak apresentaram maior peso corporal, consumo de ração médio diário, ganho em peso médio diário e melhor conversão alimentar. Entretanto, os genótipos Caboclo e Gigante Negro apresentaram menores consumo de ração médio diário, ganho de peso médio diário e pior conversão alimentar. Quanto ao rendimento de cortes, observou-se que os genótipos Caboclo e Gigante Negro apresentaram os menores valores, e o Carijó, Colorpak, Pesadão Vermelho, Pescoço Pelado e Tricolor obtiveram os melhores rendimentos de pernas. Para o rendimento de peito, o Carijó e o Pesadão Vermelho obtiveram os maiores valores. A escolha do genótipo deve ser feita de acordo com o interesse do mercado, pois há diferenças no desempenho e no rendimento de carcaça e dos cortes.
\end{abstract}

Palavras-chave: frango colonial, consumo de ração, conversão alimentar, ganho de peso

\begin{abstract}
The aim of this study was to evaluate the performance characteristics and carcass of seven genotypes of alternative strains of Redbro broiler chickens. We used 840 day old male chicks, distributed in a completely randomized design, with the following Redbro strain genotypes: Caboclo, Carijo, Colorpak, Gigante Negro, Pesadão Vermelho, Pescoço Pelado and Tricolor. The broilers were housed in 28 boxes, 30 broilers per pen in masonry shed with access to a 45 square meter paddock, with four replications. The performance characteristics (feed conversion, average daily weight gain, average daily feed intake) were evaluated in the following periods: 1 to 28, 1 to 56, 1 to 70 and 1 to 85 days of age. Body weight was measured at 28, 56, 70 and 84 days of age. The carcass traits (weight and carcass yield, breast and leg) were obtained from the slaughter of two broilers per pen, at 84 days old. Statistical analyzes were performed using the "proc glm" SAS. It was found that in all periods, Colorpak genotype broilers had higher body weight, better average daily feed intake, average daily weight gain and feed conversion. However, the genotypes Caboclo and Gigante Negro had lower average daily feed intake, and worse average daily weight gain and feed conversion. As for the cuts yield, it can be observed that the genotypes
\end{abstract}

Recebido em 18 de fevereiro de 2013

Aceito em 16 de dezembro de 2013

E-mail: velosozootecnista@yahoo.com.br 
Caboclo and Gigante Negro presented the lowest values and Carijó, Colorpak, Pesadão Vermelho, Pescoço Pelado and Tricolor had the best yields for legs. For breast meat yield and weight, Carijó and Pesadão Vermelho had the highest values. The genotype choice should be in accordance with the market interest, because there are differences in performance and carcass yield and cuts.

Keywords: colonial chicken, feed intake, feed conversion, weight gain

\section{INTRODUÇÃO}

A criação de aves para a produção de carne tipo caipira é um dos segmentos da avicultura alternativa que tem se mostrado promissor, tendo em vista a fatia do mercado composta por consumidores que demandam por produtos mais saborosos (Santos et al., 2005).

Assim, a criação alternativa de frangos de corte, também chamados no Brasil de "caipira" (Região Sudeste), "colonial" (Região Sul) e "capoeira" (Região Nordeste), tem evoluído nos últimos anos, tornando-se uma atividade economicamente viável para pequenas propriedades rurais que podem explorar este nicho de mercado com produtos diferenciados (Figueiredo et al., 2001; Takahashi et al., 2006).

Para se obter lucratividade neste segmento da avicultura, pesquisas na área de genética têm sido realizadas com o objetivo de desenvolver aves mais adaptadas para melhoria dos índices produtivos da criação alternativa (Farmer et al., 1997; Lewis et al., 1997; Boelling et al., 2003).

Conhecer o desempenho dos frangos é importante para o produtor planejar aspectos direta ou indiretamente relacionados com a lucratividade da atividade (fornecimento de ração, idade de abate, etc.). Dessa forma, tornase necessária a avaliação dos genótipos comerciais atualmente disponíveis no mercado para criação em sistema semiconfinado. As informações relacionadas ao crescimento, desempenho, rendimento e qualidade da carcaça desses genótipos são importantes para o aumento da lucratividade desse sistema de produção (Dourado et al., 2009).

O presente trabalho foi realizado com o objetivo de comparar as características de desempenho (conversão alimentar, ganho em peso médio diário e consumo de ração médio diário); peso e rendimento de carcaça; peso e rendimento de peito; e peso e rendimento de pernas, de sete genótipos de frangos tipo caipira.

\section{MATERIAL E MÉTODOS}

O experimento foi conduzido no setor de Avicultura do Departamento de Zootecnia da Universidade Federal dos Vales do Jequitinhonha e Mucuri, situado no campus JK, em Diamantina-MG, durante o período de 21 de fevereiro a 16 de maio de 2011.

Foram utilizados 840 pintos de um dia, machos, provenientes de sete genótipos de frangos tipo caipira da linhagem Redbro: Caboclo, Carijó, Colorpak, Gigante Negro, Pesadão Vermelho, Pescoço Pelado e Tricolor, distribuídos em um delineamento inteiramente ao acaso, com quatro repetições (boxes) para cada genótipo. Os frangos foram alojados em 28 boxes de dimensões $2,00 \times 2,00 \mathrm{~m}$, sendo 30 frangos por boxe, em galpão de alvenaria coberto por telhas de fibrocimento. A partir dos 28 dias de idade, os frangos tiveram acesso a um piquete de $30 \mathrm{~m}^{2}$, formado por forrageira do tipo Tifton, gênero Cynodon.

As rações utilizadas foram formuladas à base de milho e farelo de soja, para as fases inicial (um a 28 dias), crescimento (28 a 56 dias) e final (56 a 84 dias), as quais podem ser visualizadas na Tab. 1, conforme informações de composições e digestibilidade dos ingredientes apresentados em Rostagno et al. (2005), Mendonça et al. (2008), Nagib Nascimento et al. (2009a,b), Pinheiro et al. $(2011 \mathrm{a}, \mathrm{b})$.

As rações foram fornecidas à vontade, 24 horas por dia, até os 70 dias de idade. Após esse período, os frangos passaram por restrição alimentar quantitativa e receberam ração à vontade apenas das nove às 16 horas.

O peso corporal dos frangos e o consumo de ração foram mensurados ao nascer, aos 14,28 , $42,56,70$ e aos 84 dias de idade. 
Parâmetros de desempenho...

Tabela 1. Composição das rações nas três fases de criação das aves

\begin{tabular}{|c|c|c|c|}
\hline Ingredientes (\%) & 1 a 28 dias & 28 a 56 dias & 56 a 84 dias \\
\hline Milho moído & 56,792 & 62,518 & 71,793 \\
\hline Farelo de soja $45 \%$ & 36,302 & 30,822 & 24,089 \\
\hline Inerte (areia fina) & 2,558 & 3,000 & 0,914 \\
\hline Fosfato bicálcico & 2,044 & 1,327 & 1,212 \\
\hline Calcário calcítico & 1,429 & 1,196 & 1,094 \\
\hline Sal comum & 0,457 & 0,331 & 0,254 \\
\hline DL- metionina & 0,217 & 0,174 & 0,260 \\
\hline Suplemento vitamínico ${ }^{1}$ & 0,100 & 0,100 & 0,100 \\
\hline Suplemento mineral ${ }^{2}$ & 0,100 & 0,100 & 0,100 \\
\hline Óleo de soja & 0,000 & 0,311 & 0,184 \\
\hline L- lisina HCL & 0,000 & 0,120 & 0,000 \\
\hline Total & 100,000 & 100,000 & 100,000 \\
\hline \multicolumn{4}{|l|}{ Composição química calculada } \\
\hline Proteína bruta $(\%)$ & 21,27 & 19,35 & 17,00 \\
\hline Energia metabolizável (kcal/Kg) & 2750 & 2850 & 3000 \\
\hline Lisina digestível (\%) & 1,04 & 1,00 & 0,76 \\
\hline Metionina digestível (\%) & 0,51 & 0,44 & 0,50 \\
\hline Metionina + cistina digestível $(\%)$ & 0,80 & 0,71 & 0,75 \\
\hline Cálcio $(\%)$ & 1,16 & 0,88 & 0,80 \\
\hline Fósforo disponível (\%) & 0,48 & 0,35 & 0,32 \\
\hline
\end{tabular}

${ }^{\mathrm{I}}$ Suplemento vitamínico por kg de produto: vit. A 3.750.000UI; vit. $\mathrm{D}_{3} 750.000 \mathrm{UI}$; vit. E $7500 \mathrm{mg}$; vit $\mathrm{K}_{3} 1.000 \mathrm{mg}$; vit. $\mathrm{B}_{1} 750 \mathrm{mg}$; vit. $\mathrm{B}_{2} 1.500 \mathrm{mg}$; vit. $\mathrm{B}_{6} 1500 \mathrm{mg}$; vit. $\mathrm{B}_{12} 7.500 \mathrm{mcg}$; vit. $\mathrm{C} 12.500 \mathrm{mg}$; biotina $30 \mathrm{mg}$; niacina $10.000 \mathrm{mg}$; ácido fólico $375 \mathrm{mg}$; ácido pantotênico $3.750 \mathrm{mg}$; colina $10.000 \mathrm{mg}$; metionina $400.000 \mathrm{mg}$.

${ }^{2}$ Suplemento mineral por kg de produto: selênio $45 \mathrm{mg}$; iodo $175 \mathrm{mg}$; ferro $12.525 \mathrm{mg}$; cobre $2.500 \mathrm{mg}$; manganês 19.500mg; zinco $13.750 \mathrm{mg}$; prom. Prod $15.000 \mathrm{mg}$; coccidiostático $10.000 \mathrm{mg}$; antioxidante (B.H.T) 500mg.

As características de desempenho zootécnico avaliadas foram: ganho em peso médio diário (GPMD), consumo de ração médio diário (CRMD) e conversão alimentar (CA), para os períodos: um a 28 , um a 56 , um a 70 e um a 84 dias de idade; e peso corporal (PC) aos 28, 56, 70 e 84 dias de idade; ainda foi avaliado o desempenho (GPMD, CRMD e CA) e a idade média, em dias, para atingir o peso $(2300 \mathrm{~g})$ ao abate (idade $2300 \mathrm{~g}$ ), conforme publicado no Ofício Circular DIPOA N ${ }^{\circ}$ 02/2012 (Mapa, 2012). Aos 85 dias de idade, foram abatidos dois frangos de cada parcela, totalizando oito frangos por genótipo, após jejum de sólidos de seis horas. Foram, então, avaliados peso corporal ao abate; peso (PCARC) e rendimento (RCARC) de carcaça (carcaça constituída de cabeça e pés); peso (PPEITO) e rendimento (RPEITO) de peito; e peso (PPERNAS) e rendimento (RPERNAS) de pernas, sendo a perna a soma dos cortes coxa e sobrecoxa.

As análises estatísticas foram realizadas utilizando-se o "proc glm" do SAS (2002), segundo o modelo:

$$
\mathrm{Y}_{\mathrm{ijk}}=\mathrm{u}_{\mathrm{k}}+\mathrm{G}_{\mathrm{ik}}+\mathrm{e}_{\mathrm{ijk}}
$$

em que:

$\mathrm{Y}_{\mathrm{ijk}}=$ valor observado da característica $\mathrm{k}$, na repetição j, do genótipo i $(i=1,2, \ldots, 7 ; j=1,2,3$, $4 ; \mathrm{k}=1,2, \ldots, 27)$;

$\mathrm{u}_{\mathrm{k}}=$ média da característica $\mathrm{k}$;

$\mathrm{G}_{\mathrm{ik}}=$ efeito do genótipo i na característica $\mathrm{k}$

$\mathrm{e}_{\mathrm{ijk}}=$ erro aleatório associado à observação $\mathrm{Y}_{\mathrm{ijk}}$.

Para comparação entre as médias, foi utilizado o teste de médias de Tukey $(\mathrm{P} \leq 0,05)$.

\section{RESULTADOS E DISCUSSÃO}

Observaram-se diferenças significativas $(\mathrm{P} \leq 0,05)$ entre os genótipos em todas as características avaliadas (Tab. 2, 3, 4, 5 e 6).

Verificou-se que, em todos os períodos, os frangos do genótipo Colorpak apresentaram maior PC, diferindo, assim, estatisticamente, dos demais genótipos, como pode ser visualizado na Tab. 2. Pode ser observado também que, em 
todos os períodos, os genótipos Gigante Negro e Caboclo apresentaram menores PC. De acordo com Pym (2005), os frangos têm sido selecionados para aumentar a taxa de crescimento; como consequência lógica, ocorreu aumento do consumo de alimento, o que melhorou a eficiência e antecipou a idade de abate desses animais.

Tabela 2. Peso corporal (PC, em gramas) para os genótipos Caboclo, Carijó, Colorpak, Gigante Negro, Pesadão Vermelho, Pescoço Pelado e Tricolor em diferentes idades

\begin{tabular}{lcccc}
\hline Genótipo & 28 dias & 56 dias & 70 dias & 84 dias \\
\hline Caboclo & $633,36 \mathrm{e}$ & $1837,73 \mathrm{~d}$ & $2369,81 \mathrm{~d}$ & $2910,53 \mathrm{~d}$ \\
Carijó & $954,05 \mathrm{ab}$ & $2791,46 \mathrm{~b}$ & $3299,90 \mathrm{~b}$ & $3850,84 \mathrm{bc}$ \\
Colorpak & $986,39 \mathrm{a}$ & $3057,69 \mathrm{a}$ & $3645,96 \mathrm{a}$ & $4227,22 \mathrm{a}$ \\
Gigante Negro & $686,52 \mathrm{~d}$ & $1964,44 \mathrm{~d}$ & $2458,90 \mathrm{~d}$ & $3003,21 \mathrm{~d}$ \\
Pesadão Vermelho & $928,44 \mathrm{bc}$ & $2795,60 \mathrm{~b}$ & $3342,22 \mathrm{~b}$ & $3915,31 \mathrm{~b}$ \\
Pescoço Pelado & $905,95 \mathrm{c}$ & $2605,87 \mathrm{c}$ & $3097,79 \mathrm{c}$ & $3638,84 \mathrm{c}$ \\
Tricolor & $941,46 \mathrm{bc}$ & $2720,57 \mathrm{bc}$ & $3283,74 \mathrm{~b}$ & $3912,12 \mathrm{~b}$ \\
\hline Coeficiente de variação & 2,21 & 2,99 & 2,48 & 2,57 \\
\hline
\end{tabular}

Médias na mesma coluna, seguidas por diferentes letras, diferem pelo teste Tukey a 5\% de significância.

As exigências do Ofício Circular DIPOA $\mathrm{N}^{\mathrm{O}}$ 007/99 (Mapa, 1999), entre outras diretrizes, determinavam que as aves "tipo caipira" deviam ser criadas por um período mínimo de 85 dias. Com a recente alteração na idade de abate, publicada no Ofício Circular DIPOA N ${ }^{\circ}$ 02/2012 (Mapa, 2012), que reduziu a idade mínima de abate para 70 dias, verifica-se que todos os genótipos estudados no presente trabalho atingiram o PC preconizado para o abate (2300g).

Neste sentido, destacam-se os genótipos Caboclo e Gigante Negro que apresentaram crescimento mais lento, levando mais tempo para atingir o peso médio mínimo estipulado de $2300 \mathrm{~g}$, seguidos pelos genótipos Pescoço Pelado,
Carijó, Tricolor, Pesadão Vermelho e Colorpak, respectivamente. Pela Tab. 3, verifica-se que o genótipo Colorpak apresentou maior consumo de ração médio diário (CRMD), diferindo estatisticamente de todos os genótipos avaliados e em todos os períodos estudados. O genótipo Caboclo apresentou menor CRMD em todos períodos avaliados, seguido pelo genótipo Gigante Negro. Este resultado vai ao encontro da justificativa apresentada anteriormente, uma vez que os frangos dos genótipos Caboclo e Gigante Negro apresentaram uma taxa de crescimento mais lenta e visualmente um comportamento de pastejo mais ativo, tendendo a passar mais tempo no piquete e, assim, ingerindo menos ração que os frangos Colorpak.

Tabela 3. Consumo de ração médio diário (CRMD, em gramas) para os genótipos Caboclo, Carijó, Colorpak, Gigante Negro, Pesadão Vermelho, Pescoço Pelado e Tricolor nos diferentes períodos

\begin{tabular}{lrrrr}
\hline Genótipo & $1 \mathrm{a} 28$ dias & $1 \mathrm{a} 56$ dias & $1 \mathrm{a} 70$ dias & $1 \mathrm{a} 84$ dias \\
\hline Caboclo & $43,76 \mathrm{~d}$ & $72,73 \mathrm{c}$ & $83,47 \mathrm{c}$ & $96,30 \mathrm{c}$ \\
Carijó & $57,32 \mathrm{ab}$ & $101,38 \mathrm{~b}$ & $112,69 \mathrm{~b}$ & $126,44 \mathrm{~b}$ \\
Colorpak & $60,43 \mathrm{a}$ & $114,96 \mathrm{a}$ & $132,07 \mathrm{a}$ & $145,04 \mathrm{a}$ \\
Gigante Negro & $48,45 \mathrm{c}$ & $68,43 \mathrm{c}$ & $81,77 \mathrm{c}$ & $95,36 \mathrm{c}$ \\
Pesadão Vermelho & $56,47 \mathrm{~b}$ & $105,18 \mathrm{ab}$ & $116,69 \mathrm{~b}$ & $129,69 \mathrm{~b}$ \\
Pescoço Pelado & $56,10 \mathrm{~b}$ & $98,26 \mathrm{~b}$ & $110,17 \mathrm{~b}$ & $122,20 \mathrm{~b}$ \\
Tricolor & $56,39 \mathrm{~b}$ & $100,12 \mathrm{~b}$ & $111,83 \mathrm{~b}$ & $124,71 \mathrm{~b}$ \\
\hline Coeficiente de variação & 2,95 & 5,86 & 4,98 & 3,84 \\
\hline
\end{tabular}

Médias na mesma coluna, seguidas por diferentes letras, diferem pelo teste Tukey a 5\% de significância.

Madeira et al. (2010) não encontraram diferenças significativas entre os genótipos de frangos tipo caipira Master Griss e Pesadão Vermelho em relação ao consumo de ração, os quais diferiram entre os frangos Label Rouge, que apresentaram menor consumo de ração. Carrijo et al. (2002), em pesquisa com linhagens de frango de corte tipo colonial em sistema semi-intensivo de criação, também verificaram efeito do genótipo para o consumo de ração. 
Hellmeister Filho et al. (2003), ao utilizarem os genótipos Pinto Preto Pesado de Pasto Pescoço Pelado de Piracicaba, Label Rouge, Paraíso Pedrês e Caipirinha da ESALQ, observaram que o menor consumo de ração foi verificado na linhagem Pinto Preto Pesado de Pasto Pescoço Pelado de Piracicaba, enquanto o maior foi na linhagem Label Rouge.
O ganho de peso corporal de todos os genótipos pode ser visualizado na Tab. 4. O maior GPMD em todos os períodos avaliados foi obtido pelos frangos do genótipo Colorpak, e os menores pelas aves dos genótipos Caboclo e Gigante Negro.

Tabela 4. Ganho de peso médio diário (GPMD, em gramas), para os genótipos Caboclo, Carijó, Colorpak, Gigante Negro, Pesadão Vermelho, Pescoço Pelado e Tricolor, nos diferentes períodos

\begin{tabular}{lrrrr}
\hline Genótipo & $1 \mathrm{a} 28$ dias & $1 \mathrm{a} \mathrm{56}$ dias & $1 \mathrm{a} 70$ dias & 1 a 84 dias \\
\hline Caboclo & $21,25 \mathrm{e}$ & $34,37 \mathrm{~d}$ & $33,30 \mathrm{~d}$ & $34,19 \mathrm{~d}$ \\
Carijó & $32,87 \mathrm{ab}$ & $49,25 \mathrm{~b}$ & $46,66 \mathrm{~b}$ & $45,44 \mathrm{~b}$ \\
Colorpak & $33,79 \mathrm{a}$ & $53,88 \mathrm{a}$ & $51,51 \mathrm{a}$ & $49,84 \mathrm{a}$ \\
Gigante Negro & $23,10 \mathrm{~d}$ & $32,13 \mathrm{~d}$ & $34,56 \mathrm{~d}$ & $35,28 \mathrm{~d}$ \\
Pesadão Vermelho & $31,94 \mathrm{bc}$ & $49,31 \mathrm{~b}$ & $47,26 \mathrm{~b}$ & $46,20 \mathrm{~b}$ \\
Pescoço Pelado & $30,88 \mathrm{c}$ & $45,79 \mathrm{c}$ & $43,66 \mathrm{c}$ & $42,83 \mathrm{c}$ \\
Tricolor & $32,16 \mathrm{bc}$ & $47,85 \mathrm{bc}$ & $46,32 \mathrm{~b}$ & $46,09 \mathrm{~b}$ \\
\hline Coeficiente de variação & 2,36 & 3,05 & 2,52 & 2,61 \\
\hline
\end{tabular}

Médias na mesma coluna, seguidas por diferentes letras, diferem pelo teste Tukey a 5\% de significância.

Madeira et al. (2010) observaram que o ganho de peso dos frangos foi influenciado pelo genótipo. Os frangos do genótipo Ross apresentaram maior ganho de peso se comparados aos Master Griss e Pesadão Vermelho, que não diferiram entre si. Esses autores justificaram que os frangos Label Rouge apresentaram menor ganho de peso em relação aos Ross, provavelmente porque os frangos Ross passaram por melhoramento para ganho de peso rápido e não abandonaram o boxe, exercitando-se menos que os outros, na área de pastejo. Essa falta de exercício, observada pelos autores, também foi observada no presente estudo com alguns genótipos, como o Colorpak, o que pode justificar seu maior GPMD em todos os períodos avaliados.

Santos et al. (2005) observaram um maior potencial para crescimento nos frangos tipo caipira Paraíso Pedrês em relação aos ISA Label.

Pela Tab. 5, observa-se que, no período de um a 28 dias de idade, verificou-se que os genótipos Caboclo e Gigante Negro obtiveram a pior conversão alimentar. Entretanto, para os outros períodos, não houve diferença significativa da conversão alimentar entre os genótipos.

Tabela 5. Conversão alimentar (CA, em g/g) para os genótipos Caboclo, Carijó, Colorpak, Gigante Negro, Pesadão Vermelho, Pescoço Pelado e Tricolor, nos diferentes períodos

\begin{tabular}{lcccc}
\hline Genótipo & $1 \mathrm{a} 28$ dias & $1 \mathrm{a} 56$ dias & $1 \mathrm{a} 70$ dias & $1 \mathrm{a} 84$ dias \\
\hline Caboclo & $2,06 \mathrm{a}$ & $2,26 \mathrm{a}$ & $2,50 \mathrm{a}$ & $2,82 \mathrm{a}$ \\
Carijó & $1,75 \mathrm{~b}$ & $2,05 \mathrm{a}$ & $2,41 \mathrm{a}$ & $2,78 \mathrm{a}$ \\
Colorpak & $1,79 \mathrm{~b}$ & $2,13 \mathrm{a}$ & $2,56 \mathrm{a}$ & $2,91 \mathrm{a}$ \\
Gigante Negro & $2,09 \mathrm{a}$ & $1,99 \mathrm{a}$ & $2,36 \mathrm{a}$ & $2,70 \mathrm{a}$ \\
Pesadão Vermelho & $1,77 \mathrm{~b}$ & $2,13 \mathrm{a}$ & $2,47 \mathrm{a}$ & $2,81 \mathrm{a}$ \\
Pescoço Pelado & $1,81 \mathrm{~b}$ & $2,14 \mathrm{a}$ & $2,52 \mathrm{a}$ & $2,85 \mathrm{a}$ \\
Tricolor & $1,75 \mathrm{~b}$ & $2,09 \mathrm{a}$ & $2,41 \mathrm{a}$ & $2,71 \mathrm{a}$ \\
\hline Coeficiente de variação & 2,96 & 6,63 & 5,55 & 4,01 \\
\hline
\end{tabular}

Médias na mesma coluna, seguidas por diferentes letras, diferem pelo teste Tukey a 5\% de significância.

Como era de se esperar, verificou-se que a CA piorou com o avançar da idade do frango. A piora na CA dos frangos no período final de criação se deve ao fato de esses frangos estarem próximos a atingir a taxa de máximo crescimento antes dos 84 dias, quando perdem a eficiência em converter o alimento ingerido em peso corporal, sobretudo em virtude de esse ganho ser 
proporcionalmente maior em gordura (Santos et al., 2005). Segundo Kessler et al. (2000), durante o crescimento de frangos de corte, após os frangos terem atingido seu máximo crescimento, há uma mudança no perfil do crescimento, caracterizada por redução na taxa de crescimento, acompanhada por menor deposição de proteína e maior de gordura.

Dentre alguns trabalhos de literatura, destacamse Hellmeister Filho et al. (2003), os quais verificaram que a linhagem Pinto Preto Pesado de Pasto Pescoço Pelado de Piracicaba apresentou melhores valores de CA, em comparação com a linhagem Label Rouge. Savino et al. (2007) observaram que o genótipo Caipirão da ESALQ apresentou melhor conversão alimentar em relação aos genótipos Embrapa 041 e Carijó Barbada. E ainda, Takahashi et al. (2006) não encontraram diferença para conversão alimentar entre os genótipos Paraíso Pedrês, Label Rouge e Caipirinha da ESALQ, no período inicial de criação.

Os frangos dos genótipos Carijó, Colorpak e Pesadão Vermelho apresentaram menor tempo para atingir a idade ao abate (Idade 2300), diferindo estatisticamente $(\mathrm{P} \leq 0,05)$ dos demais genótipos. Os frangos dos genótipos Caboclo e
Gigante Negro apresentaram as maiores idades 2300, não diferindo entre si (Tab. 6).

Ao se comparar o CRMD, que pode ser visualizado para todos os genótipos na Tab. 6, verificou-se que não houve diferença entre os genótipos Colorpak, Pesadão Vermelho e Pescoço Pelado, que apresentaram um maior CRMD. Os genótipos Caboclo e Gigante Negro, assim como na idade 2300, apresentaram os menores valores para CRMD, diferindo estatisticamente dos demais genótipos.

Os maiores GPMD foram observados para os genótipos Carijó e Colorpak, que não diferiram entre si (Tab. 6). Assim como na idade 2300 e no CRMD, os genótipos Caboclo e Gigante Negro tiveram os piores resultados no GPMD, e também tiveram os piores valores de conversão alimentar, não diferindo estatisticamente do genótipo Pescoço Pelado. À exceção dos genótipos Caboclo e Gigante Negro, os demais genótipos não diferiram estatisticamente na conversão alimentar. Este resultado encontrado era o esperado, pois os frangos Caboclo e Gigante Negro têm um padrão de crescimento considerado lento, por isso demoraram mais tempo para atingir o peso de abate de $2300 \mathrm{~g}$, conforme o Ofício Circular DIPOA N 02/2012 (Mapa, 2012).

Tabela 6. Médias das variáveis idade aos 2300g (idade 2300), ganho de peso médio diário (GPMD, em gramas), consumo de ração médio diário (CRMD, em gramas) e conversão alimentar (CA, em g/g) para os genótipos Caboclo, Carijó, Colorpak, Gigante Negro, Pesadão Vermelho, Pescoço Pelado e Tricolor

\begin{tabular}{lrrrr}
\hline Genótipo & Idade 2300 & \multicolumn{1}{c}{ CRMD } & GPMD & CA \\
\hline Caboclo & $69,50 \mathrm{a}$ & $91,81 \mathrm{c}$ & $33,24 \mathrm{~d}$ & $2,76 \mathrm{a}$ \\
Carijó & $49,50 \mathrm{bc}$ & $113,22 \mathrm{~b}$ & $47,40 \mathrm{ab}$ & $2,38 \mathrm{~b}$ \\
Colorpak & $47,50 \mathrm{c}$ & $123,47 \mathrm{a}$ & $49,06 \mathrm{a}$ & $2,51 \mathrm{~b}$ \\
Gigante Negro & $67,25 \mathrm{a}$ & $97,36 \mathrm{c}$ & $34,54 \mathrm{~d}$ & $2,81 \mathrm{a}$ \\
Pesadão Vermelho & $50,00 \mathrm{bc}$ & $116,81 \mathrm{ab}$ & $46,46 \mathrm{bc}$ & $2,51 \mathrm{~b}$ \\
Pescoço Pelado & $52,50 \mathrm{~b}$ & $115,85 \mathrm{ab}$ & $44,46 \mathrm{c}$ & $2,60 \mathrm{ab}$ \\
Tricolor & $51,00 \mathrm{~b}$ & $112,08 \mathrm{~b}$ & $45,73 \mathrm{bc}$ & $2,45 \mathrm{~b}$ \\
\hline Coeficiente de variação & 2,39 & 4,00 & 2,19 & 3,92 \\
\hline
\end{tabular}

Médias na mesma coluna, seguidas por diferentes letras, diferem pelo teste Tukey a 5\% de significância.

Pode ser observado que os maiores pesos ao abate, conforme é apresentado na Tab. 7, foram observados pelos frangos dos genótipos Carijó, Colorpak, Pesadão Vermelho e Tricolor, e os genótipos Caboclo e o Gigante Negro tiveram os menores pesos. Com relação às características de carcaça (Tab. 7), pode-se observar que os frangos dos genótipos Caboclo e Gigante Negro apresentaram o menor peso de carcaça (PCARC) $(\mathrm{P} \leq 0,05)$, não havendo diferença entre os demais genótipos; já o rendimento de carcaça (RCARC) não diferiu estatisticamente entre nenhum dos genótipos avaliados. Resultado semelhante foi encontrado por Santos et al. (2005) com os frangos tipo caipira Paraíso Pedrês e ISA Label. 
Tabela 7. Peso corporal ao abate, peso (PCARC) e rendimento (RCARC) de carcaça, peso (PPEITO) e rendimento (RPEITO) de peito e peso (PPERNAS) e rendimento (RPERNAS) de pernas, para os genótipos Caboclo, Carijó, Colorpak, Gigante Negro, Pesadão Vermelho, Pescoço Pelado e Tricolor, abatidos aos 85 dias de idade

\begin{tabular}{|c|c|c|c|c|c|c|c|}
\hline Genótipo & $\begin{array}{l}\text { Peso } \\
\text { Abate }\end{array}$ & $\begin{array}{c}\text { PCARC } \\
(\mathrm{g})\end{array}$ & $\begin{array}{c}\text { RCARC } \\
(\%)\end{array}$ & $\begin{array}{l}\text { PPEITO } \\
(\mathrm{g})\end{array}$ & $\begin{array}{l}\text { RPEITO } \\
(\%)\end{array}$ & $\begin{array}{c}\text { PPERNAS } \\
(\mathrm{g})\end{array}$ & $\begin{array}{c}\text { RPERNAS } \\
(\%)\end{array}$ \\
\hline Caboclo & $2782,75 c$ & $2161,3 b$ & $77,63 a$ & $521,75 b$ & $24,10 \mathrm{c}$ & $659,88 b$ & $30,55 \mathrm{ab}$ \\
\hline Carijó & $3974,50 \mathrm{ab}$ & $3287,9 \mathrm{a}$ & $83,04 \mathrm{a}$ & $985,00 \mathrm{a}$ & $29,93 a$ & $962,13 a$ & $29,29 \mathrm{ab}$ \\
\hline Colorpak & $4185,25 a$ & $3414,4 \mathrm{a}$ & $81,54 \mathrm{a}$ & $996,00 \mathrm{a}$ & $29,12 \mathrm{ab}$ & $964,25 \mathrm{a}$ & $28,20 \mathrm{~b}$ \\
\hline Gigante Negro & $2984,62 c$ & $2362,3 b$ & $79,14 a$ & $606,50 \mathrm{~b}$ & $25,65 \mathrm{bc}$ & $708,50 \mathrm{~b}$ & $29,98 \mathrm{ab}$ \\
\hline Pesadão Vermelho & $4108,00 \mathrm{ab}$ & $3270,0 \mathrm{a}$ & $79,72 \mathrm{a}$ & $1014,13 a$ & $31,00 \mathrm{a}$ & $935,13 a$ & $28,57 \mathrm{ab}$ \\
\hline Pescoço Pelado & $3756,75 b$ & $3132,3 \mathrm{a}$ & $80,77 \mathrm{a}$ & $925,13 \mathrm{a}$ & $29,50 \mathrm{ab}$ & $898,00 \mathrm{a}$ & $29,26 a b$ \\
\hline Tricolor & $3912,25 \mathrm{ab}$ & $3059,8 \mathrm{a}$ & $80,17 \mathrm{a}$ & $844,50 \mathrm{a}$ & $27,50 \mathrm{abc}$ & $950,88 \mathrm{a}$ & $31,14 \mathrm{a}$ \\
\hline Coef. variação & 7,29 & 6,37 & 3,00 & 10,88 & 6,41 & 7,41 & 4,27 \\
\hline
\end{tabular}

O padrão de desempenho dos frangos com relação ao PPEITO foi exatamente igual ao observado para PCARC, em que os genótipos Caboclo e Gigante Negro também apresentaram menores resultados, e os demais não diferiam entre si $(\mathrm{P}>0,05)$. Com relação ao RPEITO, os frangos dos genótipos Carijó e Pesadão Vermelho apresentaram maiores médias, não diferindo do Colorpak, Pescoço Pelado e Tricolor. O genótipo Caboclo apresentou o menor RPEITO, não diferindo do Gigante Negro e Tricolor. Novamente, verificou-se que os genótipos Caboclo e Gigante Negro tenderam a apresentar os piores desempenhos, quando comparados aos demais genótipos avaliados.

Quanto ao desempenho dos genótipos em relação à característica PPERNAS, os frangos dos genótipos Caboclo e Gigante Negro obtiveram os piores resultados, assim como no PPEITO e no PCARC; os demais genótipos, entretanto, não apresentaram diferenças entre si $(\mathrm{P}>0,05)$. Para a característica RPERNAS, os frangos do genótipo Tricolor obtiveram o melhor resultado, não havendo diferença $(\mathrm{P}>0,05)$ entre os genótipos Caboclo, Carijó, Gigante Negro, Pesadão Vermelho e Pescoço Pelado; já os frangos do genótipo Colorpak apresentaram o pior RPERNAS, diferindo do genótipo Tricolor.

Coelho et al. (2007) não encontraram efeito significativo entre os genótipos Caipirão da ESALQ, Pinto Preto Pesado de Pasto de Pescoço Pelado de Piracicaba, Caipirinha da ESALQ, Carijó Barbado, Paraíso Pedrês, Embrapa 041, Label Rouge, Paraíso Pelado para rendimento de pernas.
Verificou-se, portanto, que, quando se avaliaram as características de peso de carcaça e cortes, os genótipos Caboclo e Gigante Negro tenderam a apresentar os piores resultados. Mas, quando se avaliaram as características de rendimento de carcaça e pernas, foi detectada diferença no desempenho entre os genótipos avaliados.

Destaca-se que o mercado consumidor brasileiro de frango tipo caipira demanda principalmente o frango inteiro, e como o padrão de carcaça hoje preconizado é uma carcaça não muito grande, devido à redução do tamanho das famílias brasileiras, verifica-se que os genótipos avaliados neste trabalho tenderam a apresentar um peso de carcaça elevado, sugerindo-se que, para atender à demanda de mercado, estes frangos precisam ser abatidos em menores idades, em consonância com o Ofício Circular DIPOA $N^{\circ}$ 02/2012 (Mapa, 2012). Esta redução na idade ao abate permite ainda reduzir o custo de produção (melhor eficiência alimentar), além de diminuir disputas entre machos por serem mais jovens, bem como evitar que os frangos sejam submetidos a programa alimentar alternativo, como forma de adequar o seu peso de abate.

\section{CONCLUSÕES}

Os frangos do genótipo Colorpak apresentaram, de maneira geral, o melhor desempenho zootécnico, e os frangos Caboclo e Gigante Negro os piores desempenhos. Comportamento semelhante foi observado para peso e rendimento dos cortes. 


\section{AGRADECIMENTO}

Os autores agradecem o aporte financeiro e o apoio recebidos da Avifran, Capes, CNPq, Fapemig e Globoaves.

\section{REFERÊNCIAS}

BOELLING, D.; GROEN, A.F.; SORENSEN, P. et al. Genetic improvement of livestosk for organic farming systems. Livestock Sci., v.80, p.79-88, 2003.

CARRIJO, A.S.; MENEZES, G.P.; SILVA, M.J. et al. Avaliação de linhagens alternativas na criação de frango tipo caipira. Rev. Bras. Cienc. Avic., v.4, p.84, 2002.

COELHO, A.A.D; SAVINO, V.J.M.; ROSÁRIO, M.F. et al. Nota prévia: características da carcaça e da carne de genótipos de frangos caipiras. Braz. J. Food Technol., v.10, p.9-15, 2007.

DOURADO, L.R.B.; SAKOMURA, N.K.; NASCIMENTO, D.C.N. et al. Crescimento e Desempenho de Linhagens de Aves Pescoço Pelado Criadas em Sistema Semi - Confinado. Cienc. Agrotec., v.33, p.875-881, 2009.

FARMER, L.J.; PERRY, G.C.; LEWIS, P.D. et al. Responses of two genotypes of chicken to the diet sands tocking densities of conventional UK and Label Rouge production systems. 2. Sensory attributes. Meat Sci., v.47, p.77-93, 1997.

FIGUEIREDO, E.A.P.; PAIVA, D.P.; ROSA, P.S. et al. Diferentes denominações $\mathrm{e}$ classificação brasileira de produção alternativa de frangos. In: CONFERÊNCIA APINCO DE CIÊNCIA E TECNOLOGIA AVÍCOLAS, 2. 2001, São Paulo. Anais... Campinas: Fundação Apinco de Ciência e Tecnologias Avícolas, 2001. p.209-222.

HELLMEISTER FILHO, P.; MENTEN, J.F.M.; SILVA, M.A.N. et al. Efeito do genótipo e do Sistema de Criação sobre do Desempenho de Frangos Tipo Caipira. Rev. Bras. Zootec., v.32, p.1883-1889, 2003.

KESSLER, A.M.; SNIZEK, P.N.; BRUGALLI, I. Manipulação da quantidade de gordura na carcaça de frangos. In: FUNDAÇÃO DE CIÊNCIA E TECNOLOGIA AVÍCOLAS, 2000, São Paulo. Anais... Campinas: FACTA, 2000. p.107-133.
LEWIS, P.D.; PERRY, G.C.; FARMER, L.J. et $a l$. Responses of two genotypes of chicken to the diets and stocking densities typical of UK and "Label Rouge" production systems. 1. Performance, behavior and carcass composition. Meat Sci., v.45, p.501-516, 1997.

MADEIRA, L.A.; SARTORI, J.R.; ARAUJO, P.C. et al. Avaliação do desempenho e do rendimento de carcaça de quatro linhagens de frangos de corte em dois sistemas de criação. Rev. Bras.Zootec., v.39, p.2214-2221, 2010.

MAPA. Ministério da Agricultura, Pecuária e Abastecimento. BRASIL. Departamento de Inspeção de Produtos de Origem Animal/ divisão de operações industriais. Ofício Circular DOI/DIPOA n 007/99 de 19/05/1999. Registro do Produto "Frango Caipira ou Frango Colonial" ou "Frango Tipo ou Estilo Caipira" ou "Tipo ou Estilo Colonial". Brasília, DF: Ministério da Agricultura e do Abastecimento, 1999.

MAPA. Ministério da Agricultura, Pecuária e Abastecimento. BRASIL. Departamento de Inspeção de Produtos de Origem Animal/ divisão de operações industriais. Ofício Circular DOI/DIPOA n ${ }^{\circ}$ 02/2012 de 01/02/2012. Registro do Produto "Frango Caipira ou Frango Colonial" ou "Frango Tipo ou Estilo Caipira" ou "Tipo ou Estilo Colonial". Brasília, DF: Ministério da Agricultura e do Abastecimento, 2012.

MENDONÇA, M.O.; SAKOMURA, N.K.; SANTOS, F.R. et al. Níveis de energia metabolizável para machos de corte de crescimento lento criados em semiconfinamento. Rev. Bras. Zootec., v.37, p.1433-1440, 2008.

NAGIB NASCIMENTO, D.C.; SAKOMURA, N.K.; SIQUEIRA, J.C. et al. Exigências de lisina digestível para aves de corte da linhagem ISA Label criadas em semiconfinamento. Arq. Bras. Med. Vet. Zootec., v.61, p.1128-1138, 2009a.

NAGIB NASCIMENTO, D.C.; SAKOMURA, N.K.; SIQUEIRA, J.C. et al. Exigências de metionina + cistina digestível para aves de corte ISA Label criadas em semiconfinamento. Rev. Bras. Zootec., v.38, p.869-878, 2009 b.

PINHEIRO, S.R.F.; SAKOMURA, N.K.; NAGIB NASCIMENTO, D.C. et al. Níveis nutricionais de fósforo disponível para aves de corte ISA Label criadas em semiconfinamento. Rev. Bras. Zootec., v.40, p.361-369, 2011 a. 
PINHEIRO, S.R.F.; SAKOMURA, N.K.; SIQUEIRA, J.C. et al. Níveis nutricionais de cálcio para aves de corte ISA Label criadas sob semiconfinamento. Arq. Bras. Med. Vet. Zootec., v.63, p.231-238, $2011 \mathrm{~b}$.

PYM, R.A.E. Genetic aspects of food intake and food utilization efficiency for growth in chickens. In: AUSTRALIAN POULTRY SCIENCE SYMPOSIUM, 17., 2005, Australia. Proceedings... Sydney: The World's Poultry Science Association, 2005. p.153-162.

ROSTAGNO, H.S.; ALBINO, L.F.T.; DONZELE, J.L. et al. Composição de alimentos e exigências nutricionais - Tabelas Brasileiras. Viçosa, MG: Universidade Federal de Viçosa, 2005. 141p.

SANTOS, A.L.; SAKOMURA, N.K.; FREITAS, E.R. et al. Estudo do Crescimento, Desempenho, Rendimento de Carcaça e Qualidade de Carne de Três Linhagens de Frango de Corte. Rev. Bras. Zootec., v.34, p.158 9-1598, 2005.
SAVINO, V.J.M.; COELHO, A.A.D.; ROSÁRIO, M.F. et al. Avaliação de materiais genéticos visando à produção de frango caipira em diferentes sistemas de alimentação. Rev. Bras. Zootec., v.36, p.578-583, 2007.

STATISTICAL Analysis Systems - SAS. User's guide: Version 9.1, Cary: 2002. v.2, 1052p.

TAKAHASHI, S.E.; MENDES, A.A.; SALDANHA, E.S.P.B. et al. Efeito do sistema de criação sobre o desempenho e rendimento de carcaça de frangos de corte tipo colonial. Arq. Bras. Med. Vet. Zootec., v.58, p.624-632, 2006. 